ÉGYPTE monde arabe

\section{Égypte/Monde arabe}

4 | 1990

Démocratie et démocratisation dans le monde arabe

\title{
Démocratie et démocratisation dans le monde arabe
}

\section{François Burgat}

\section{(2) OpenEdition}

12 Journals

Édition électronique

URL : https://journals.openedition.org/ema/336

DOI : $10.4000 /$ ema.336

ISSN : 2090-7273

\section{Éditeur}

CEDEJ - Centre d'études et de documentation économiques juridiques et sociales

\section{Édition imprimée}

Date de publication : 31 décembre 1990

ISSN : 1110-5097

\section{Référence électronique}

François Burgat, « Démocratie et démocratisation dans le monde arabe », Égypte/Monde arabe [En ligne], 4 | 1990, mis en ligne le 08 juillet 2008, consulté le 07 juillet 2022. URL : http://

journals.openedition.org/ema/336 ; DOI : https://doi.org/10.4000/ema.336

Ce document a été généré automatiquement le 7 juillet 2022.

Tous droits réservés 


\title{
Démocratie et démocratisation dans le monde arabe
}

\author{
François Burgat
}

1 Les articles qui composent ce dossier ont en commun d'avoir été présentés au $3^{\text {ème }}$ colloque franco-égyptien de politologie organisé par le Centre d'Études Politiques de l'Université du Caire et le CEDEJ, du 29 septembre au 1er octobre 1990, sur le thème "Démocratie et démocratisation dans le monde arabe ».

2 Les Actes de cette rencontre seront donnés ultérieurement à lire dans leur intégralité aux lecteurs arabophones aussi bien que francophones. Avant le classique travail éditorial, une telle entreprise implique toutefois un long préalable consacré aux seules opérations de traduction et requiert des délais qui se plient plus ou moins heureusement à l'actualité des sujets abordés : première raison pour laquelle Égypte/ Monde Arabe a décidé de présenter sans attendre - en tout ou en partie ${ }^{1}$ - quelques-unes des contributions disponibles en langue française. Sans prétendre - par un choix aléatoire dicté notamment par la proximité des auteurs - représenter l'entier éventail des approches mises en œuvre et des terrains choisis pour les développer, la seconde ambition de ce dossier est de donner aux lecteurs de la revue un aperçu - fût-il partiel de travaux que leur destination éditoriale rend habituellement moins accessibles. Sur des registres et avec dés ambitions variés, les contributions de Jean-Claude Vatin (Les partis (pris) démocratiques: perceptions occidentales de la démocratisation dans le monde arabe), Michel Camau (Trois questions à propos de la « démocratisation» dans le monde arabe), Pierre-Jean Luizard (L'improbable démocratie en Irak: le piège de l'État nation), JeanFrançois Legrain (Les élection étudiantes en Cisjordanie) et François Burgat (Les islamistes et la transition démocratique) s'inscrivent dans une problématique dont Alain Roussillon avait tracé les axes.

3 Même si les contre-exemples attestent que le processus de démocratisation qui, après l'Amérique latine. L'Europe de l'Est et, dans une moindre mesure l'Asie, saisit le monde arabe depuis fa fin de la guerre froide (...) est loin d'être général et linéaire, écrivait en substance A. Roussillon, « c'est précisément le fait que les problèmes qui se posent dans les Etats qui n'ont pas entamé une évolution démocratique ou à tout le moins leur 
libéralisation soient fondamentalement de même nature que ceux des États où l'alternative démocratique semble à l'ordre du jour, qui incite à tenter de saisir en termes de démocratisation - et de ses difficultés - les évolutions en cours à l'échelle de l'ensemble du monde arabe. »

4 Trois « ordres de raisons » et trois « ordres de problèmes » attestent pour A. Roussillon l'origine de cette centralité et " c'est la façon dont se hiérarchisent ces trois niveaux » sociologique politico-idéologique et économique qui concourt à différencier les expériences en cours :

- «La persistance, voire le renforcement de modes de mobilisation et d'organisation (...) infraétatiques auxquels se heurtent les tentatives de prise de contrôle autoritaire de la société par l'État, que ces modes aient été conduits sous le timbre de la construction de la Nation, du socialisme ou de la modernisation » (...)

- «L'intégration sur la scène politique formelle de l'islam politique, dont il apparaît de plus eh plus clairement que celui-ci ne saurait être réduit à quelques groupuscules agités mais représente une part variable, mais toujours considérable, de l'opinion publique » (...)

- «La nécessité, à la fois d'ordre interne et externe, diplomatique, de mettre en phase des options économiques effectives, de plus en plus généralement libérales (...) avec le fonctionnement du système politique et de l'idéologie ». classification.

\section{NOTES}

1. Une partie seulement de l'appareil statistique relatif à l'analyse de Jean-François Legrain a été reproduite. Une section de l'analyse de François Burgat est présentée sous forme résumée. 